This is the final peer-reviewed accepted manuscript of:

Costa, M., Bonetti, L., Vignali, V., Bichicchi, A., Lantieri, C., \& Simone, A. (2019). Driver's visual attention to different categories of roadside advertising signs. Applied Ergonomics, 78, 127-136.

The final published version is available online at:

https://doi.org/10.1016/i.apergo.2019.03.001

Rights / License:

The terms and conditions for the reuse of this version of the manuscript are specified in the publishing policy. For all terms of use and more information see the publisher's website.

This item was downloaded from IRIS Università di Bologna (https://cris.unibo.it/)

When citing, please refer to the published version. 


\title{
Driver's visual attention to different categories of roadside advertising signs
}

Marco Costa ${ }^{\mathrm{a}, *}$, Leonardo Bonetti ${ }^{\mathrm{b}, \mathrm{a}}$, Valeria Vignalic ${ }^{\mathrm{c}}$, Arianna Bichicchi ${ }^{\mathrm{c}}$, Claudio Lantieri ${ }^{\mathrm{c}}$,

Andrea Simone ${ }^{\mathrm{c}}$

${ }^{a}$ Department of Psychology, University of Bologna, Italy ${ }^{b}$ Center for Music in the Brain, Department of Clinical Medicine, Aarhus University \& The Royal Academy of Music Aarhus/Aalborg, Denmark ${ }^{\mathrm{c}}$ Department of Civil, Chemical, Environmental and Material Engineering, University of Bologna, Italy

\author{
A B S T R A C T
}

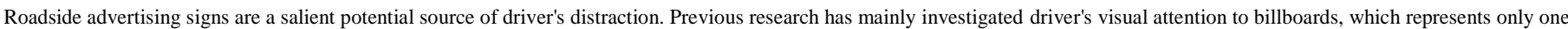

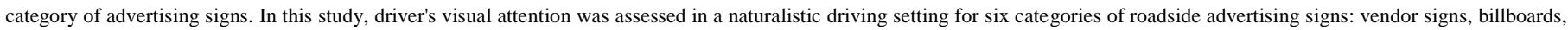

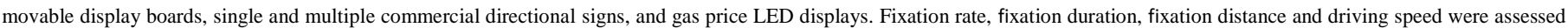

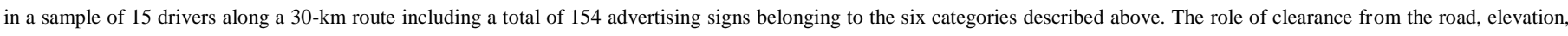

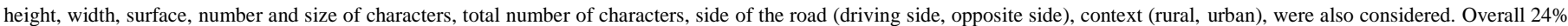

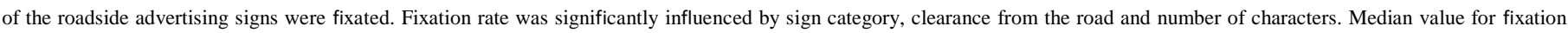

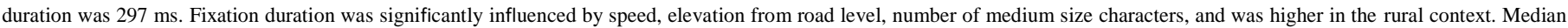
value for fixation distance was

$58.10 \mathrm{~m}$, and was significantly influenced by advertising sign category, character count and speed

Keywords:

Roadside advertising signs

Eye movements

Distraction

Fixation duration

Fixation distance 


\section{Introduction}

Road advertising signs can adversely affect driver's behavior, representing a salient potential danger for driving. Specifically, advertising signs may distract from the driving task, obstruct visibility at intersections or driveways, present a physical obstacle to vehicles going off road, or interfere with attention to formal traffic signs. In our study, we assessed eye fixations, fixation duration, and distance of fixation to six categories of roadside advertising signs, considering driver's speed, sign placement, size, and other design parameters. Differently from previous research, we explored the impact of six different categories of advertising signs: billboards, vendor signs, single and multiple commercial directional signs, movable display boards, and gas price LED displays.

Studies on accident statistics have often included advertisements as a critical cause. The first example is represented by Ady (1967), who recorded accident rates before and after the installation of billboards on different road segments. One billboard placed at the corner of a sharp bend and brightly illuminate appeared particularly critical.

Advertising signs placed on curves are particularly problematic due to their potential distracting effect in a context of high cognitive load (Land and Lee, 1994). However, the positioning of advertising signs on curves is often requested by advertisement agencies because they receive more fixations than advertisements placed laterally on straight road segments (Beijer et al., 2004).

Advertising billboards are highly conspicuous due to their size, coloration, and layout, all designed to be attention-grabbing. Whenever the driver's attention is diverted from the driving task and addressed to irrelevant information such as advertising signs, driving could be impaired (e.g., Lansdown et al., 2015; Wallace, 2003). Wallace (2003), in a review, concluded that there was a real risk of increased accident vulnerability, but that this effect is situation specific, and is due to the additive effect of the advertising sign to other environmental critical aspects.

Many researchers have used driving simulation to study the effect of road advertisement on attentional resources and driving performance, even if the external validity of data obtained with a simulator is reduced in comparison to ecological studies with data collected in real naturalistic driving conditions.

The effect of elevation on advertising sign conspicuity was investigated by Crundall et al. (2006) who found that street-level-advertisements received longer fixations that 3-m raised advertisements. In Bendak and Al-Saleh (2010) driving performance was assessed in a driving simulator in two conditions, one with and one without roadside advertising signs. Two driving performance parameters, drifting from lane and recklessly crossing dangerous intersections, were significantly worse in the condition with advertising signs. Similarly, Young et al. (2009) found that the presence of billboards adversely affected driving performance in terms of lateral control. Edquist et al. (2011) examined the level of distraction induce by billboards with the ISO standardized Lane Change Test, that involves changing lanes in response to road signs at regular intervals. They found that the presence of billboards diverted eye movements from the road ahead and delayed responses to road signs by 0.5 to $1 \mathrm{~s}$. Marciano and Yeshurun (2012) studied the perceptual load induced by roadside advertisement billboards on driving performance in a simulator. The attentional capture interfered with the ability of participants to distribute their attentional resources efficiently between the road and its sides, resulting in less effective search for critical events that in some occasions ended in accidents.

Other studies have investigated roadside advertisement using ecological settings. Beijer et al. (2004), for example, studied glance behavior of 25 drivers at advertising signs along a Toronto expressway. Averaged glance was $0.57 \mathrm{~s}$ in duration. Active signs, containing movable displays, received a significant higher number of glances than passive signs. The number of long glances was also greater for active signs compared to the passive ones. Topolšek et al. (2016) recorded eye movements while participants performed $10 \mathrm{~km}$ of urban driving including 56 traffic signs and 31 advertising signs. They found a 0.75 correlation between visual detection of traffic signs and visual detection of advertising signs. Mean detection of advertisements was 0.37. Decker et al. (2015) performed a systematic literature review on the effects of billboards on driver visual behavior. The results highlighted that about $10-20 \%$ of all glances at billboards were greater than 0.75 $\mathrm{s}$, and that active billboards drew more and longer glances than passive billboards. Moreover, there is now general agreement that digital billboards attract more attention and cause greater impairment to driving performance when compared with static billboards. In general, rapidly changing stimuli near the roadway may represent a potential safety concern (Belyusar et al., 2016).

Driver's distraction is also significantly affected by the emotional arousal induced by the advertising signs. Chan and Singhal (2013) found that driving performance was differentially affected by the valence of the advertisement emotional content. Megías et al. (2011) investigated the role of the emotional content of roadside advertisements on modulation of attention in a risky driving scenario and the results indicated that the number of fixations and total fixation time elicited by affect-laden advertisements were greater than those elicited by neutral advertisements. Negative pictures received later gaze disengagement than positive and neutral images, and this attentional capture resulted in lower eye fixations to the road.

Signs that are placed in the driver's line of sight are much more fixated in comparison to roadside signs. For example, in the study conducted by Lantieri et al. (2015) eye movements were recorded in a naturalistic driving setting with gateways that marked the transition from rural to urban sections that differed for their design. An extended town sign placed $6.5 \mathrm{~m}$ high over the driver's lane, received significantly more visual attention in comparison to traditional town signs placed on the roadside.

Costa et al. (2014) argued that the lateral placement of traffic signs is one of the main reasons for the poor visual detection of vertical traffic signs. Costa et al. (2014), in an ecological setting of $8.34 \mathrm{~km}$ driving, found that only $25.06 \%$ of vertical traffic signs were glanced by drivers.

Road advertising signs strongly differ for their form, illumination and color (Elliot and Maier, 2014), all critical features that are able to variously affect driver's attention/distraction. Visual processing of signs with logos, for example, is slightly higher than that for guide signs (Kaber et al., 2015). Furthermore, conspicuous colours such as yellow, orange, red or various kinds of illumination or reflective materials can easily capture driver's visual attention (Costa et al., 2016; Lesley, 1995). Similarly, text length, font and size have been shown to have a direct influence on fixation frequency, duration, and distance on print advertisements (Rayner et al., 2001). 
Previous research focused quite exclusively on billboards, but road sides host many other types of advertising signs that can contribute to the driver's distraction. The main aim of our study was therefore to assess driver's visual behavior in response to categories of roadside advertisement that were never investigated by previous research. In addition to billboards, we included vendor signs, directional signs for companies, restaurants, commercial activities (distinguishing between single and multiple directional signs), movable display boards and gas price LED displays.

Regulations and restrictions on roadside billboards are highly diversified. In U.S. billboards are regulated by the Highway Beautification Act since 1965, with some states in which they are prohibited (e.g., Vermont, Alaska, Hawaii, and Maine), and others in which they are subjected to specific requirements. According to the Italian regulation (Italian Highway Code, 1992) road advertisements outside urban areas, should not exceed $6 \mathrm{~m}^{2}$, with the exception of vendor signs parallel to the street that should not exceed $20 \mathrm{~m}$. The inferior border should be higher than $1.5 \mathrm{~m}$ from the street level. Inside urban areas they are subjected to local regulations. Directional signs for commercial and tourist locations are rectangular with a size between $1 \times 0.2 \mathrm{~m}$ and $1.5 \times 0.3 \mathrm{~m}$. Multiple directional signs should not exceed six signs mounted on a same pole. Extra care is requested in the use of the red color to avoid confusion with traffic signs. Roadside billboards should be installed at a distance exceeding $3 \mathrm{~m}$ from road shoulders, and at a distance greater than $250 \mathrm{~m}$ from intersections. They are prohibited in curves.

Visual attention to advertising signs was assessed by eye movement recording (Land and Tatler, 2009). Eye movements are highly correlated with the path of visual attention (Nuthmann and Einhäuser, 2015; Nuthmann et al., 2017) and therefore the probability to attract fixations could be an indirect measure of a roadside advertisement salience. Eye movements during driving tend to follow specific patterns. Several studies, for example, have found that horizontal eye movements are dominant over vertical movements (Crundall and Underwood, 1998; Mourant and Rockwell, 1972). Most fixations are directed to the focus of expansion (i.e., the point in space where all optical flow vectors intersect), with the driver looking straight ahead. When not looking at the focus of expansion, the eyes usually scan the left or right visual scene with horizontal saccades, looking for driving-relevant information (Underwood et al., 2003).

The SEEV model (Horrey et al., 2006; Wickens, 2007, 2008; Wickens and McCarley, 2008) establishes four components that predict allocation of visual attention (e.g., in a scan path) across any large scale environment such as the road: saliency, effort, expectancy, and value. Saliency expresses the bottom-up attention capturing property of a stimulus (e.g., the size of a roadside advertisement and the contrast of its graphical design). Effort expresses the inhibition of attention shifts due to the costs of large saccadic movements, or head movements (e.g., the lower visual attention to roadside advertisements that are placed with higher clearance from the road). Expectancy and value are mainly top-down processes. The first expresses the likelihood of seeing an event, and the second the importance and the relevance of the event (e.g., enhanced attention to gas price signs because the fuel light is on). In our study, we focused only on bottom-up processes, saliency and effort, as predictors of visual attention to roadside advertisements differing for their category, size, design, and content.

The main dependent variable in our study was the proportion of advertising signs that were fixated by drivers for each of the six categories. Additional dependent variables were fixation duration, driver's speed at the time of first fixation, and fixation distance (i.e., the distance at which the sign was first fixated). This last parameter was recently used by Costa et al. $(2018 \mathrm{a}, \mathrm{b})$ considering road signs, finding that the distance or first glance was in mean $51 \mathrm{~m}$. Fixation distance allows the identification of the specific road location in which the potential distraction effect can occur. Furthermore, fixation distance could be considered an indirect measure of sign conspicuity.

A further aim of the study was to relate the fixation patterns to a set of parameters that characterized advertising sign placement, size, and design. Specifically, for each of the 154 advertising signs included in this study we considered clearance from the carriageway, elevation from the road, sign height, width, surface area, text character count, and big, medium, and small text character counts.

We hypothesized that frequency of fixation to advertising signs would mirror the results of frequency for road signs as found in Costa et al. (2014), and that fixation frequency would be enhanced by a lower clearance from the carriageway, a higher elevation, size, and the amount of text. Furthermore, we hypothesized that billboards would receive higher visual attention than vendor signs, and that vendor signs would attract more attention than movable display boards and directional signs. Billboards and vendor signs, in fact, tend to be greater in size and they are specifically designed to attract attention in comparison to directional signs and movable display boards that tend to be characterized by a more informative content. We also hypothesized that the amount of text embedded in the roadside advertisement would strongly influence the amount of time in which the advertisement is glanced by the driver. Considering the urban/rural context, we suggested that advertisement in a rural context would receive higher and longer fixations due to lower density of roadside advertisements in rural environments.

\section{Method}

\subsection{Participants}

Fifteen participants were involved in the study, 10 males $\left(\mathrm{M}_{\mathrm{age}}=27.1, \mathrm{SD}=13.08\right)$ and 5 females $\left(\mathrm{M}_{\mathrm{age}}=24.53, \mathrm{SD}=0.89\right)$. All participants had normal vision and none of them wore eyeglasses or lenses, since this would have excluded eye-movement recording. Participation was on a voluntary basis. Participants, blinded to the aims of the study, were informed that the experimental purpose was to test the mobile eye recording equipment in a driving context. None of the participants had a previous experience of the experimental route used in this study. All participants were Italians and had a standard Category-B driving license. Average driving experience was 6.53 years $(\mathrm{SD}=5.41)$, while mean kilometers per year were $6292(\mathrm{SD}=3425)$.

The study was approved by the Ethics Committee of the University of Bologna and an informed consent was signed by each participant prior to the participation.

\subsection{Materials and procedure}

A BMW series 1 car was used for all participants. Eye movements were recorded with an ASL Mobile-Eye XG equipment. Sample rate was $30 \mathrm{~Hz}$ with an angular precision of $1^{\circ}$. Vehicle kinematic data (speed, GPS positioning and acceleration) were recorded with a Video-VboxPro system.

The eye-tracking system was composed by two digital high-resolution cameras, both mounted on lightweight eyeglasses. One of the camera recorded the visual scene in front of the participant while the other camera recorded the participant's eye movements (right eye). The ASL software superimposed fixation spots to the driver's visual scene in the form of a red cross with a time resolution of $33 \mathrm{~ms}$ (Fig. 1).

A calibration procedure was carried out to map eye movements to the driver's visual scene. The calibration took place in a parking lot while the car was stationary. Participants were requested to fixate 20 specific points, vertexes and centers of small objects in the visual scene. 
The Video-Vbox-Pro system consisted of two cameras positioned on the left and right frontal areas of the car roof, and a GPS antenna that was attached to the top of the car, in central position. The system recorded speed (accuracy: $\pm 1 \mathrm{~km} / \mathrm{h}$ ) and acceleration with a $20 \mathrm{~Hz}$ sample rate. The kinematic data were synchronized with the video recording of the driver's visual scene.

The experimental route was a round trip of $30 \mathrm{~km}(15+15 \mathrm{~km})$ along the B-road SP 610 "Selice-Montanara", a single carriageway, twolane-road. Lane width was $\approx 2.5 \mathrm{~m}$. The experimental route intersected six small towns, allowing the recording of both rural and urban segments. The context was rural in $47 \%$ of the route and urban in the $53 \%$ of the route.

The annual average daily traffic (AADT) along the examined road segment was 198 vehicles/day with a design speed of $50 \mathrm{~km} / \mathrm{h}$ (urban segments), and 90 $\mathrm{km} / \mathrm{h}$ (rural segments). The distinction between urban and rural segments was based on the position of entry and exit town signs. The advertising signs considered in the analysis were located on both sides of the experimental route and belonged to six different categories:

a) Billboard: roadside advertising device, freestanding or attached to abuilding, advertising products via words, symbols and pictorial displays.

b) Single directional sign: single directional signs for commercial ac-tivities and tourist attractions.

c) Multiple directional sign: multiple directional signs for commercialactivities or tourist attractions stacked on a same pole.

d) Vendor signs: signs and advertisements installed in the forecourts ofbusiness premises to draw attention to commercial services, goods for sale, or other services available at the premises. Only vendor signs that were not parallel to the road were included, since they were directly visible for the driver.

e) Gas price LED signs: signs placed at gas stations equipped with LEDdisplays that showed the prices of the different fuels.

f) Movable display boards: vendor commercials of small size presentedthrough temporary displays at ground level.

Examples of the roadside advertisement categories included in the study are shown in Fig. 2. A total of 154 signs were considered. Eightynine (57.79\%) were located on the driving side, while $65(42.21 \%)$ were located on the opposite side. The distribution and side allocation of the different categories are reported in Table 1.

Overall mean distance between two consecutive advertising signs was $169 \mathrm{~m}(\mathrm{SD}=241 \mathrm{~m})$. Density of advertising signs was higher in the urban sections $(\mathrm{M}=$ $124 \mathrm{~m}, \mathrm{SD}=188 \mathrm{~m})$ than in the rural sections $(\mathrm{M}=302 \mathrm{~m}, \mathrm{SD}=321 \mathrm{~m}): \mathrm{F}(1,153)=19.8, \mathrm{p}<.001$. Distance for consecutive advertising signs was lower at the driving side $(M=236 \mathrm{~m}, \mathrm{SD}=302 \mathrm{~m})$, than at the opposite side $(\mathrm{M}=598 \mathrm{~m}, \mathrm{SD}=897 \mathrm{~m}): \mathrm{F}(1,153)=15.75, \mathrm{p}<.001$, and was significantly affected by the type of roadside advertisement: $\mathrm{F}(4,149)=31.26, \mathrm{p}<.001$. Mean distance was $488 \mathrm{~m}(\mathrm{SD}=698)$ for billboards, $573 \mathrm{~m}(\mathrm{SD}=726)$ for vendor signs, $573 \mathrm{~m}(\mathrm{SD}=660)$ for directional signs (single and multiple directional signs), 2390 ( $\mathrm{SD}=2049$ ) for mobile vendor signs, and $4099 \mathrm{~m}$ (SD = 3460) for gas price LED signs. Fig. 3 shows the positioning of all the roadside advertisements along the route differentiating for category, context (urban vs. rural) and side (driver side vs. opposite side).

For each sign the following design parameters were considered: a) clearance from road shoulder; b) elevation from road surface; c) width; d) height; e) surface area; f) character count differentiating between small, medium, and big characters; g) total character count; h) side (driver's side - opposite side); i) context (rural - urban). The main dimensional properties for the six categories are presented in Table 2.

All measures were obtained with a Bosch GLM 40 laser telemeter. Elevation was computed as the difference between the lower sign

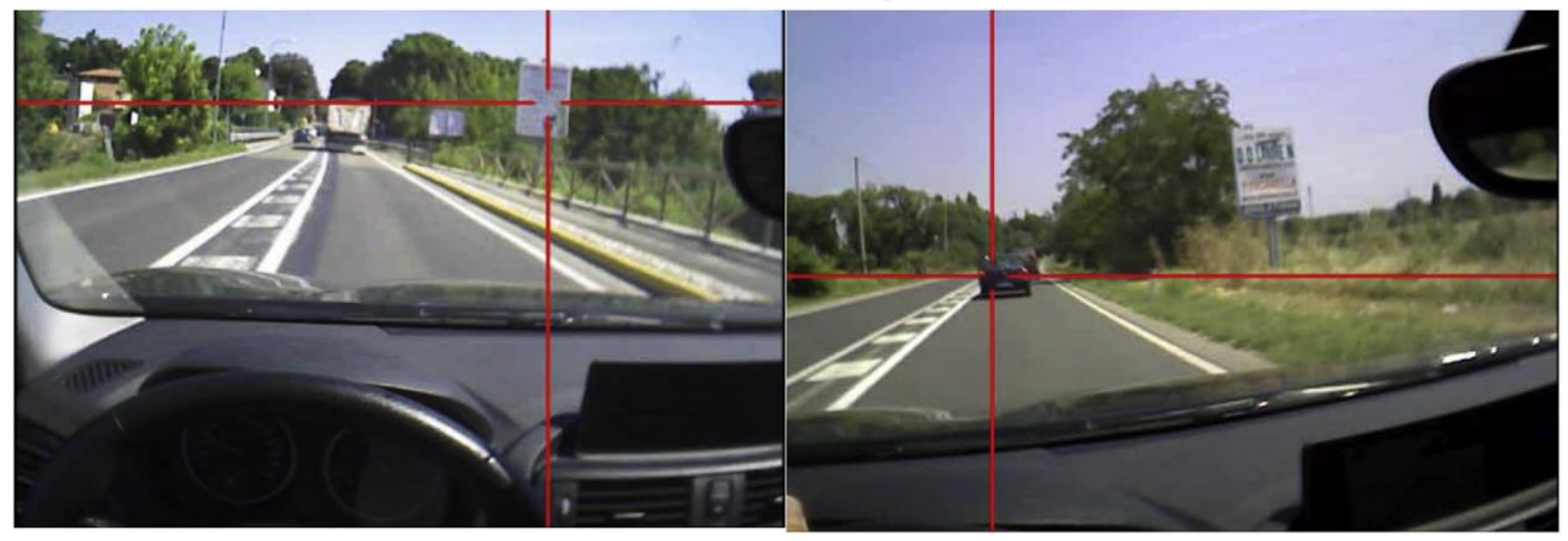

Fig. 1. Superposition of the eye tracking output to the driver's visual scene. On the left example of fixation to a roadside billboard. On the right example of billboard not fixated by the driver. 


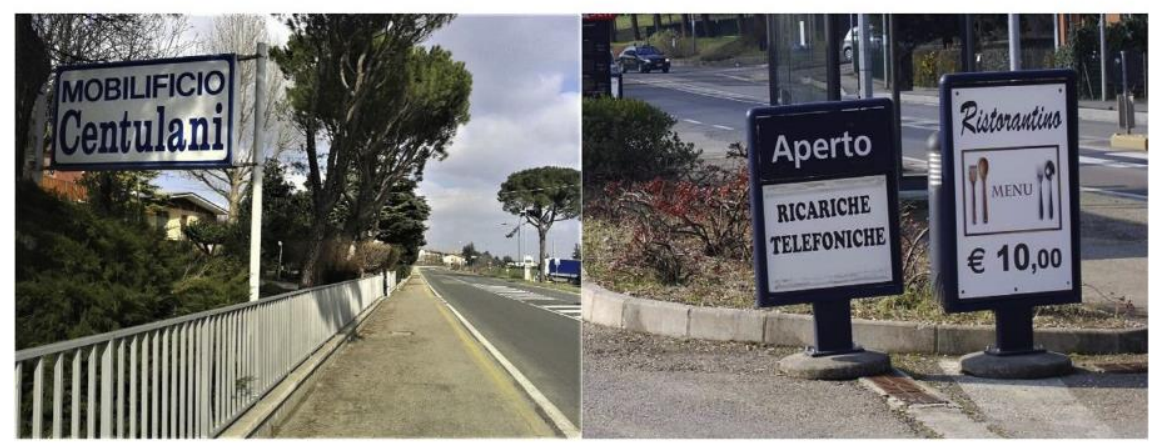

Billboard

Gas price LED sign

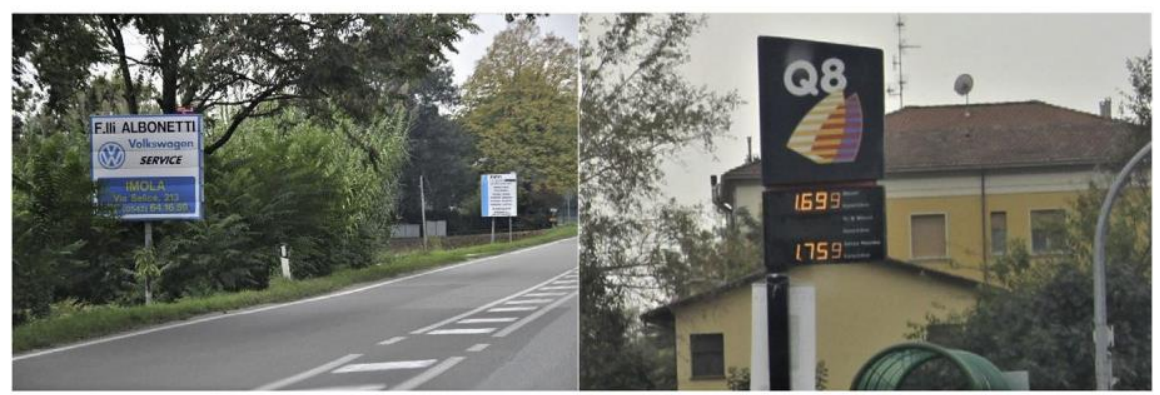

Single directional sign

Multiple directional sign

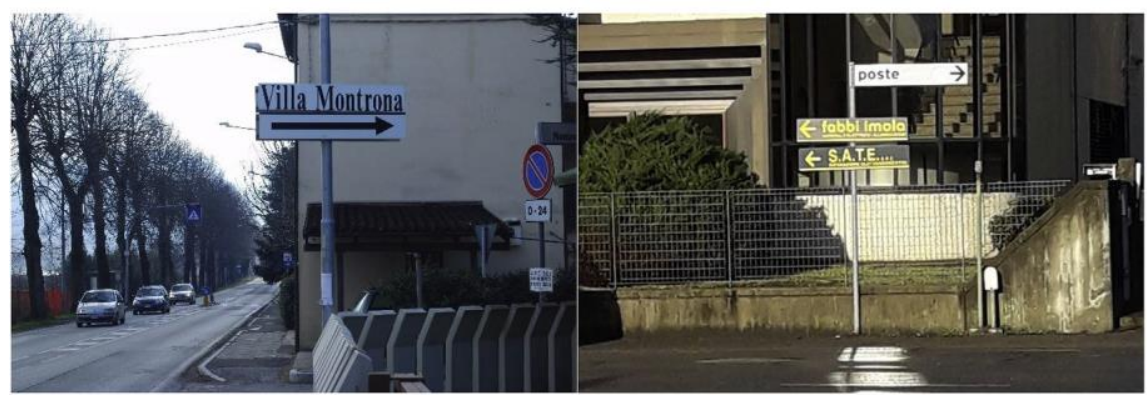

Fig. 2. Advertising sign categories included in the study.

Table 1

Distribution for side of the six advertising sign categories.

\begin{tabular}{llll}
\hline Category & Driving side & Opposite side & Total \\
\hline Vendor signs & $38(42.7 \%)$ & $26(40 \%)$ & $64(41.6 \%)$ \\
Billboards & $26(29.3 \%)$ & $24(36.9 \%)$ & $50(32.5 \%)$ \\
Multiple directional signs & $8(9 \%)$ & $6(9.2 \%)$ & $14(9.1 \%)$ \\
Single directional signs & $7(7.8 \%)$ & $4(6.2 \%)$ & $11(7.1 \%)$ \\
Movable display board & $7(7.8 \%)$ & $3(4.6 \%)$ & $10(6.5 \%)$ \\
Gas price LED signs & $3(3.4 \%)$ & $2(3.1 \%)$ & $5(3.2 \%)$ \\
Total & 89 & 65 & 154
\end{tabular}

margin and the carriageway level. Background colours of the roadside advertisements were: white (53.62\%), black (12.31\%), blue (10.14\%), green (10.14\%), brown $(8.69 \%)$, red $(2.89 \%)$, and yellow $(2.21 \%)$. Single and multiple directional signs had a black background (68\%) or white background (32\%). Text in the advertisement area was divided in 3 categories according to its height: $\leq 10 \mathrm{~cm}$ (small), $>10 \mathrm{~cm}$ and $<20 \mathrm{~cm}$ (medium), $\geq 20 \mathrm{~cm}$ (big).

Each participant drove $1 \mathrm{~km}$ before starting the experimental route to familiarize with the eye recording equipment and the car. Participants had to drive following the SP 610 road for $15 \mathrm{~km}$ until they were given instructions to return to the starting point along the same road. They did not have to plan the route or 
follow specific directional signs. Data collection was carried out from 10 to 12 a.m. and from 2 to 5 p.m. to avoid high density traffic conditions. All experimental sessions were run in weather conditions that guaranteed homogeneous visibility conditions for all participants, without rain, fog, or mist.

\subsection{Data analysis}

Fixations to road side advertising signs were assessed by a frame-byframe analysis of the ASL eye-tracking-output video. A traffic sign was considered as fixated if the fixation point (intersection point of the cross shown in Fig. 1) was positioned within the road sign surface area (AOI: area of interest) for a minimum duration of two frames $(66 \mathrm{~ms})$, to avoid the inclusion of saccadic movements. The cases of one-frame glances to the sign AOI that were discarded were 18 (3.91\%). The threshold of $66 \mathrm{~ms}$, which is fairly low in comparison to a common high-pass filtering of $100 \mathrm{~ms}$ or higher usually found in eye-tracking studies (Holmqvist et al., 2015) was dictated by the specific dynamic setting of this study that involved the recording of eye movements while driving. Velichkovsky et al. (2000), for example, reported that fixations around $60 \mathrm{~ms}$ made up around $7 \%$ of all fixations during a simulated driving task. In a real driving task, as the one considered in this study, car movements and the high-speed of the dynamical visual scene could result in very rapid fixations and saccades. Fixations recorded for two frames (66 $\mathrm{ms}$ ) accounted for $5.9 \%$ of all fixations, and three-frame fixations $(100 \mathrm{~ms})$ accounted for $7.9 \%$ of all fixations. Previous studies clearly showed that visual stimuli exposed for intervals shorter than $100 \mathrm{~ms}$ could lead to a correct identification and categorization of a visual stimulus. Specifically, Costa et al. (2018a,b) showed that a $66 \mathrm{~ms}$ presentation lead to an accuracy rate of $80 \%$ in road sign recognition. Since road signs tend to be smaller in size than road advertising signs, a fortiori, such a duration could be enough for the driver to have a gist of the advertising sign content, and therefore the exclusion of these data could have resulted in a loss of significant events.

Fixation duration was assessed as the number of adjacent frames in which the fixation point was included in the sign area. Synchronization the eye tracking output video with the Video-Vbox-Pro output video allowed the assessment of the driver's speed at the time of each fixation. The distance at which an advertising sign was first fixated was computed as the difference between the position of the first fixation to the sign, and the position in which the car was perpendicular to the roadside sign.

Fixation rate for each of the six advertising sign categories and for each participant were analyzed with a repeated-measure ANOVA that tested if the fixation rate varied significantly within the six categories and if fixation rate was significantly affected by side (driver's side, opposite side), and context (urban, rural). A preliminary analysis showed that the distributions for fixation duration and fixation distance were highly asymmetrical and positively skewed. Skewness persisted also after a log-transformation. For this reason, we applied non-parametric tests (Kruskall-Wallis and Mann-Whitney) to analyze the effects of advertising sign category, context (urban vs. rural), and side (driver's side, opposite side) on both variables.

The effects of clearance from road shoulder, width, height, surface area, elevation, number of small, medium, big text characters, and total number of text characters on fixation duration and fixation distance were analyzed with multiple linear regressions. The same parameters were entered in a binomial logistic regression to test the differences between fixated and not fixated advertising signs.

Greenhouse-Geisser correction was applied in repeated-measure ANOVAs. Pairwise comparisons with Bonferroni correction was used when comparing factors with more than two levels. Effect size was reported as Cohen partial eta square when reporting ANOVA results, and as phi when reporting Chi-square results. SPSS ver. 23 was used for all statistical computations.

\section{Results}

\subsection{Fixation rate}

Advertising signs were fixated on average with a proportion of .24 . As shown by the ANOVA results, fixation rate was significantly different between the 6 advertising sign categories: $\mathrm{F}(5,60)=6.47, \mathrm{p}=.002, \eta^{2} \mathrm{p}=.35$. Mean proportions for the six categories, in decreasing order, were: 0.31 ( \pm 0.14 ) for billboards, $0.27( \pm 0.17)$ for gas price LED signs, $0.23( \pm 0.08)$ for single directional signs, $0.23( \pm 0.08)$ for

Opposite side

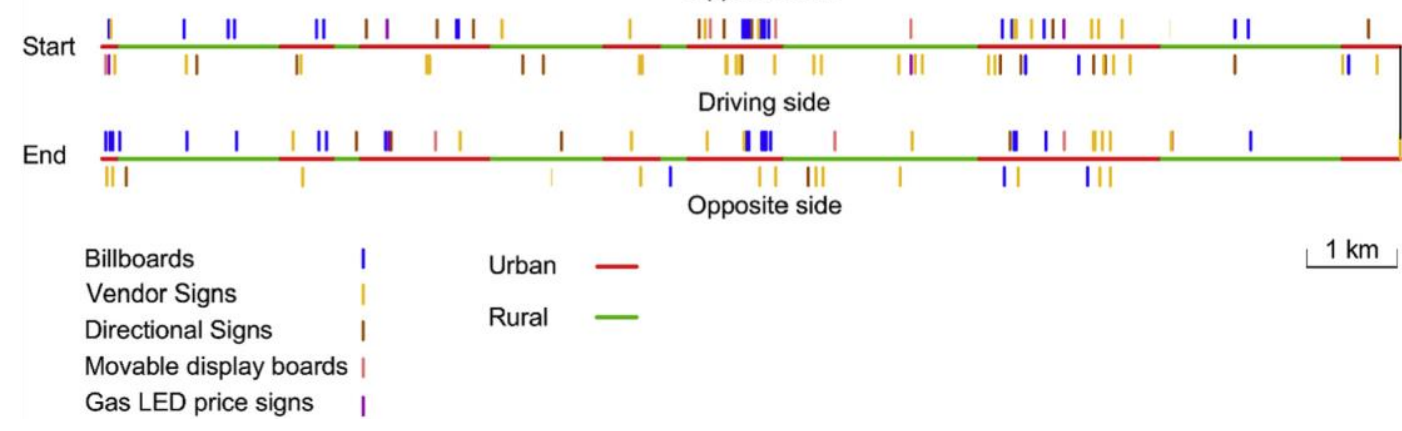

Fig. 3. Distribution of roadside advertising signs along the experimental route, differentiating for category, context (urban vs. rural), and side (driving side vs. opposite site). All the distances are in scale. The vertical black line shows the turning point between the outbound and the return section. Table 2

Dimensional properties (M and SD) of the six advertising sign categories. 


\begin{tabular}{|c|c|c|c|c|}
\hline & Clearance $(\mathrm{cm})$ & Elevation from the road $(\mathrm{cm})$ & Surface area $\left(\mathrm{m}^{2}\right)$ & $\begin{array}{l}\text { Characters } \\
\#\end{array}$ \\
\hline Vendor signs & $289(138)$ & $259(120)$ & $1.33(1.48)$ & $34(60)$ \\
\hline Billboards & $298(82)$ & $152(48)$ & $2.31(0.9)$ & $93(159)$ \\
\hline Multiple directional signs & $283(100)$ & $146(34)$ & $1.04(0.79)$ & $63(61)$ \\
\hline Single directional signs & $235(113)$ & $178(18)$ & $0.29(0.12)$ & $13(5)$ \\
\hline Movable display boards & $324(277)$ & $24(9)$ & $0.43(0.12)$ & $53(16)$ \\
\hline Gas price LED signs & $370(115)$ & $450(72)$ & $6.3(0.6)$ & $64(13)$ \\
\hline Mean & $290(125)$ & $198(111)$ & $1.57(1.41)$ & $53(101)$ \\
\hline
\end{tabular}

vendor signs, 0.16 ( \pm 0.09$)$ for multiple directional signs, and $0.12( \pm 0.12)$ for movable display boards.

Pairwise comparisons between the single categories showed a significant difference between billboards and vendor signs $(\mathrm{p}=.02)$, billboards and movable

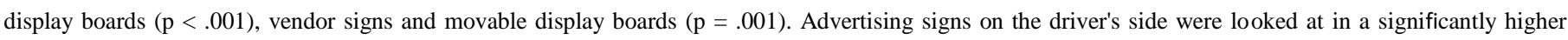
proportion $(\mathrm{M}=0.27)$ in comparison to signs located on the opposite side $(\mathrm{M}=0.21): \chi^{2}=8.71, \mathrm{p}=.003, \varphi=0.41$.

A binomial logistic regression tested the differences between fixated and not fixated signs on these variables: clearance from the road, elevation from the road,

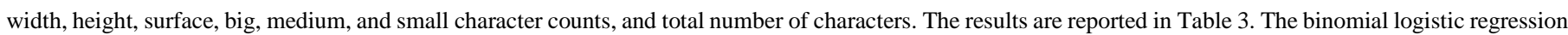

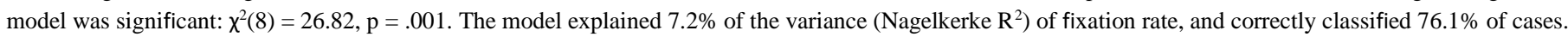

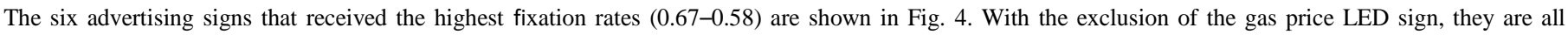
characterized by a rich text content and medium-large size. Furthermore, they are all positioned near the carriageway shoulder.

\subsection{Fixation duration}

The distribution of fixation duration is reported in Fig. 5. The distribution was highly asymmetrical and positively skewed with a kurtosis of 4.63 and an asymmetry of 2.09. Shapiro-Wilk normality test was significant $(\mathrm{p}<.001)$, showing that the distribution was not normal. Mode value was $99 \mathrm{~ms}$, median value was $297 \mathrm{~ms}$. The effect of advertisement sign category on fixation duration was tested with a Kruskal-Wallis test that was not significant ( $\mathrm{p}<.45)$. Median fixation time for the different categories were: $330 \mathrm{~ms}(\mathrm{SD}=502)$ for billboards, $264 \mathrm{~ms}(\mathrm{SD}=414)$ for vendor signs, $264 \mathrm{~ms}(\mathrm{SD}=102)$ for gas price LED signs, $231 \mathrm{~ms}(\mathrm{SD}$ $=414)$ for movable display board, $297 \mathrm{~ms}(\mathrm{SD}=357)$ for single directional signs, and $280 \mathrm{~ms}(\mathrm{SD}=338)$ for multiple directional signs.

A Mann-Whitney test checked the difference between fixations in urban versus rural context and the difference was significant $(U=17318, p=.03)$. Fixation duration was significantly higher in the rural

Table 3

context $(\mathrm{Mdn}=363 \mathrm{~ms})$ than in the urban context $(\mathrm{Mdn}=264 \mathrm{~ms})$.

The side of the road in which the sign was positioned was not critical in modulating fixation duration $(\mathrm{p}=.37)$.

In a multiple linear regression, we tested the influence of speed, clearance from road shoulder, elevation, height, width, surface area, number of characters on

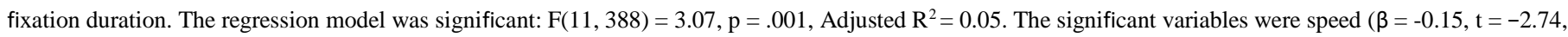
$\mathrm{p}=.006)$, elevation $(\beta=-0.17, \mathrm{t}=-2.86, \mathrm{p}=.004)$, and medium size character count $(\beta=.13, \mathrm{t}=1.99, \mathrm{p}=.04)$.

Fig. 6 shows the six advertisement signs that received the longest fixation times $(>2 \mathrm{~s})$. Their design was mainly textural, with a remarkable number of words,

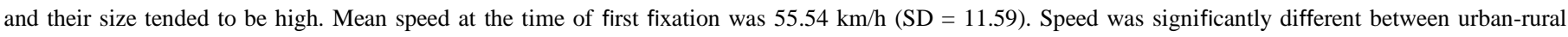
segments: $\left(\mathrm{F}(1,434)=50.82, \mathrm{p}<.001, \mathrm{\eta}_{\mathrm{p}}^{2}=.11\right)$. Mean speed in urban areas was $54.77 \mathrm{~km} / \mathrm{h}(\mathrm{SD}=10.81)$, while in rural areas it was $64.47 \mathrm{~km} / \mathrm{h}(\mathrm{SD}=11.71)$.

\subsection{Fixation distance}

Fixation distance density plot is shown in Fig. 7. The distribution was strongly positively skewed with a kurtosis of 4.29 and an asymmetry of 1.46 . ShapiroWilk normality test was significant $(\mathrm{p}<.001$ ), showing that the distribution was not normal. Median fixation distance was $58.10 \mathrm{~m}$. A Kruskal-Wallis test was used for testing the influence of roadside advertising category on fixation distance. The test was significant: $\chi^{2}=55.91, p<.001$. Median distances for the different categories, in decreasing order, were: gas price LED signs $73.16 \mathrm{~m}(\mathrm{SD}=31.50)$, billboards $69.9 \mathrm{~m}(\mathrm{SD}=38.76)$, vendor signs $57.25 \mathrm{~m}(\mathrm{SD}=35.72)$, multiple directional signs $42.15 \mathrm{~m}(\mathrm{SD}=22.17)$, movable display board $37.3 \mathrm{~m}(\mathrm{SD}=22.09)$, single directional signs $34.25 \mathrm{~m}(\mathrm{SD}=20.81)$. Median values and distribution of fixation distance for the six categories is shown in Fig. 8. Side of the road was also significant (Mann-Withney U(1) $=26.39$, $p<.001$ ). Signs positioned on the driver's side were fixated at a shorter distance $(\mathrm{Mdn}=51.99 \mathrm{~m}, \mathrm{SD}=35.72)$ than signs that were positioned in the opposite direction $(\mathrm{Mdn}=67.75 \mathrm{~m}, \mathrm{SD}=37.13$ ). Fixation distance was not significantly different in urban and rural settings. 
Descriptive statistics (M and SD) and results of the binary logistic regression that tested advertising sign size and text differences between fixated and not fixated signs.

\begin{tabular}{|c|c|c|c|c|c|}
\hline & & Fixated signs & Not-fixated signs & $x^{2}$ & $\mathrm{p}$ \\
\hline \multicolumn{2}{|c|}{ Clearance from the road $(\mathrm{cm})$} & $270.02(144.77)$ & $293.28(169.83)$ & 14.38 & $<.001$ \\
\hline \multicolumn{2}{|l|}{ Elevation $(\mathrm{cm})$} & $172.09(115.87)$ & $174.96(122.87)$ & 1.05 & ns \\
\hline \multicolumn{2}{|l|}{ Width $(\mathrm{cm})$} & $124.54(60.60)$ & $105.72(66.09)$ & 11.34 & $=.001$ \\
\hline \multicolumn{2}{|l|}{ Height (cm) } & $123.39(88.61)$ & $100.17(82.77)$ & 3.19 & ns \\
\hline \multicolumn{2}{|l|}{$\operatorname{Surface}\left(\mathrm{m}^{2}\right)$} & $1.77(1.55)$ & $1.31(1.42)$ & .37 & ns \\
\hline \multicolumn{2}{|l|}{ Characters $\geq 20 \mathrm{~cm}$ (\#) } & $3.15(5.34)$ & $2.30(4.78)$ & 4.90 & $=.02$ \\
\hline \multirow{3}{*}{\multicolumn{2}{|c|}{$\begin{array}{c}\text { Characters }>10 \mathrm{~cm} \text { and } \\
\text { Characters } \leq 10 \mathrm{~cm}(\#) \\
\text { Total characters }(\#)\end{array}$}} & $13.62(22.69)$ & $9.55(16.91)$ & 6.82 & $=.009$ \\
\hline & & $34.82(46.41)$ & $43.23(37.35)$ & 5.99 & $=.01$ \\
\hline & & $51.37(47.95)$ & $55.09(39.80)$ & 3.21 & $=.01$ \\
\hline
\end{tabular}

$\mathrm{A}(.67) \quad B(.67)$

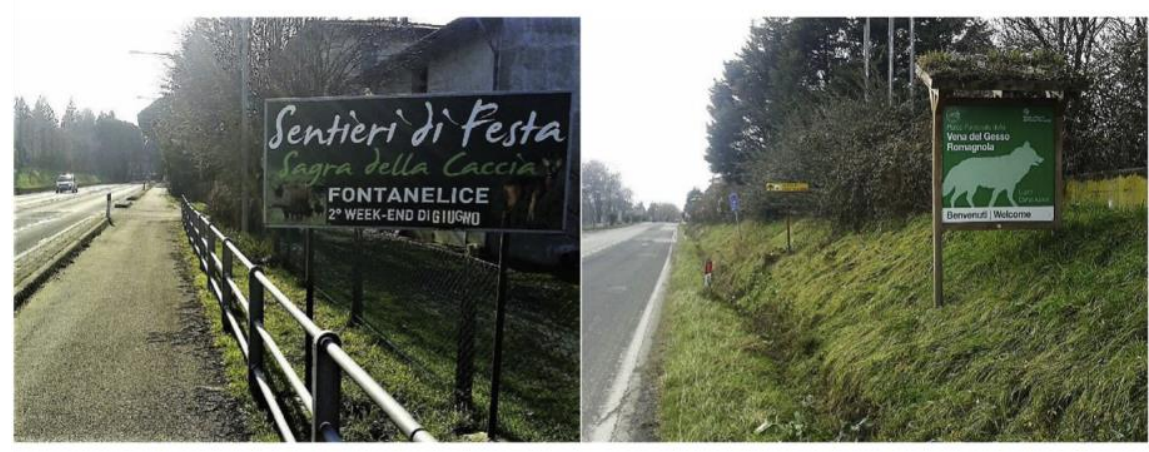

C (.58)

$\mathrm{D}(.58)$
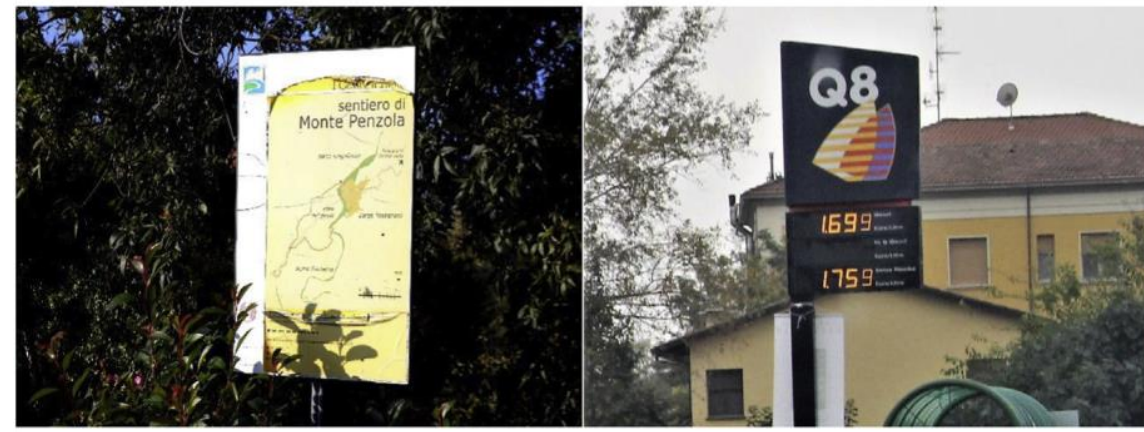

$E(.58)$

$F(.58)$

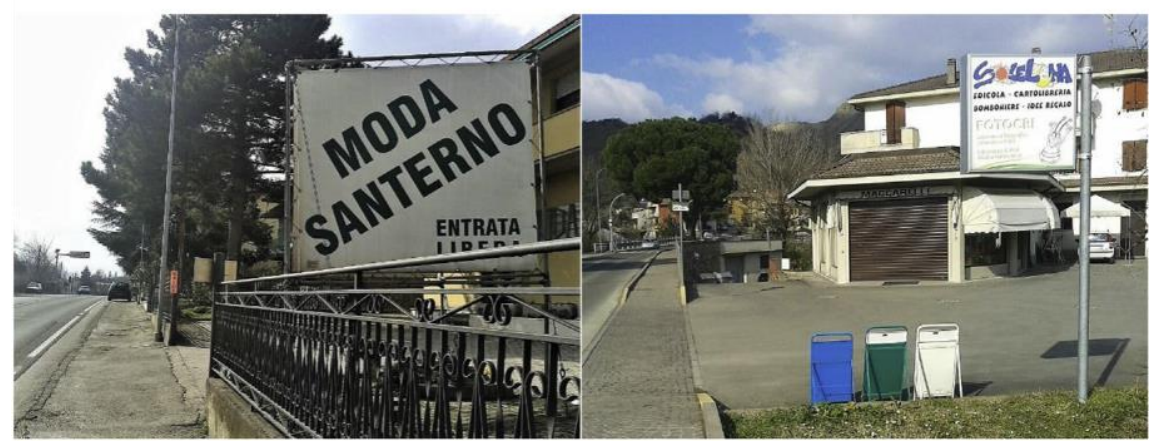

Fig. 4. The six advertising signs that received the highest fixation rate. In brackets the mean proportion of fixations for each sign. 


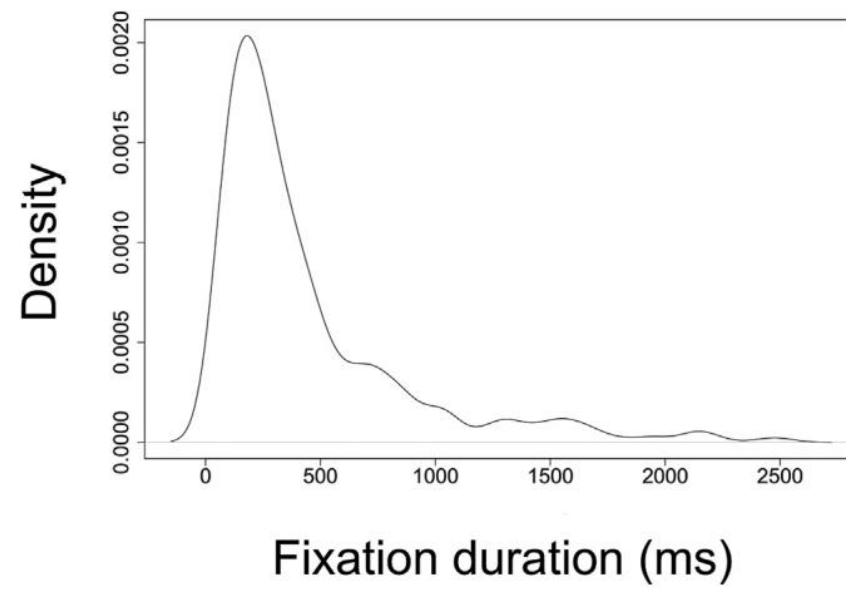

Fig. 5. Density histogram for fixation duration for all the advertising sign categories
The influence of speed, clearance from the road, elevation, height, width, surface, character count on fixation distance was tested with a multiple linear regression. The model was significant: $F(11,388)=14.78, p<.001, R^{2}=0.27$. The significant variables in the model were speed $(\beta=0.25, \mathrm{t}=5.44, \mathrm{p}<.001)$, width $(\beta=-0.20, t=-2.01, p=.04)$, surface $(\beta=0.54, t=2.68, p=.008)$, total number of characters $(\beta=0.16, t=2.05, p=.04)$, and medium size character count $(\beta=0.18$, $\mathrm{t}=3.19, \mathrm{p}=.002)$.

\section{Discussion}

The visual complexity of roadsides could contribute to attract the driver's attention, diverting it from the driving and resulting in safety issues that should be assessed and controlled. This study assessed the impact of different categories of advertising signs on the driver's visual behavior. Considering the whole sample of 154 advertising signs, the

mean fixation rate was $24 \%$, a proportion that closely matched the mean fixation rate for vertical traffic signs of $25.06 \%$ found by Costa et al. (2014). While previous research focused almost exclusively on billboards, in our study we assessed visual exploratory parameters to 

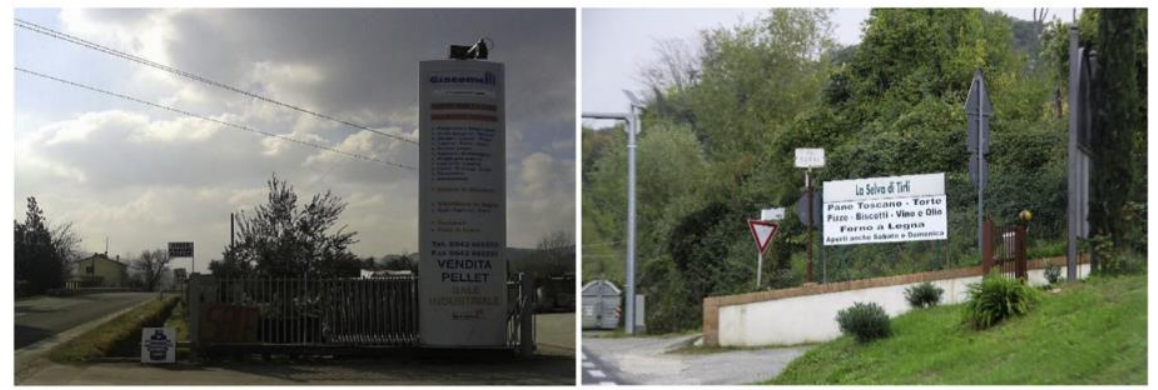

C (814 $\pm 636 \mathrm{~ms})$

$\mathrm{D}(812 \pm 873 \mathrm{~ms})$

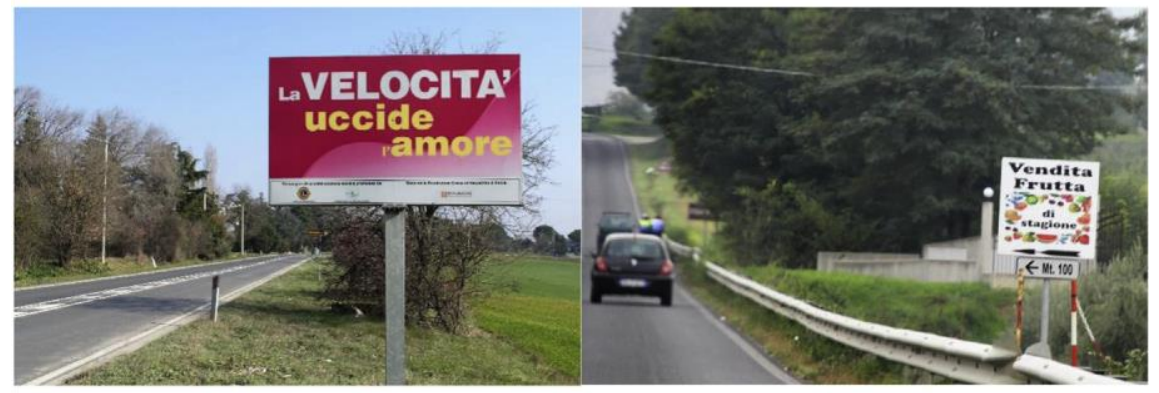

E (792 $\pm 483 \mathrm{~ms})$

$\mathrm{F}(759 \pm 527 \mathrm{~ms})$

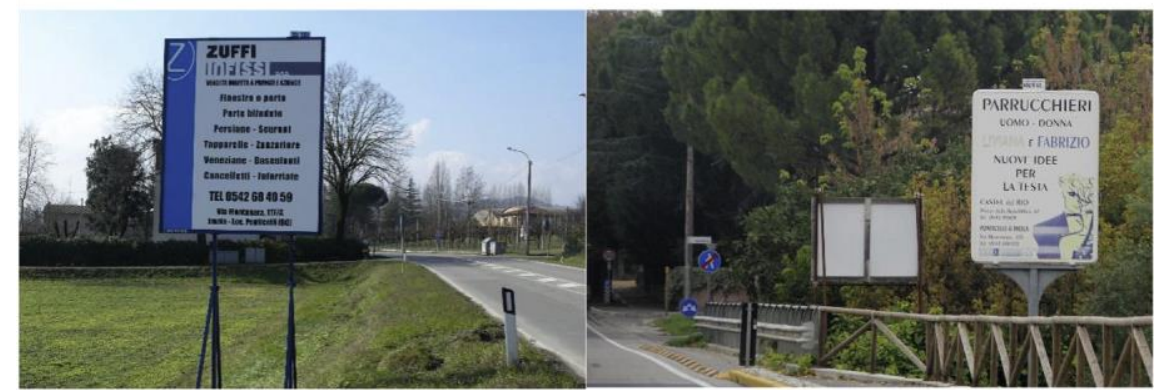

Fig. 6. The six advertising signs that received the longest fixations. In brackets the mean fixation time $( \pm \mathrm{SD})$

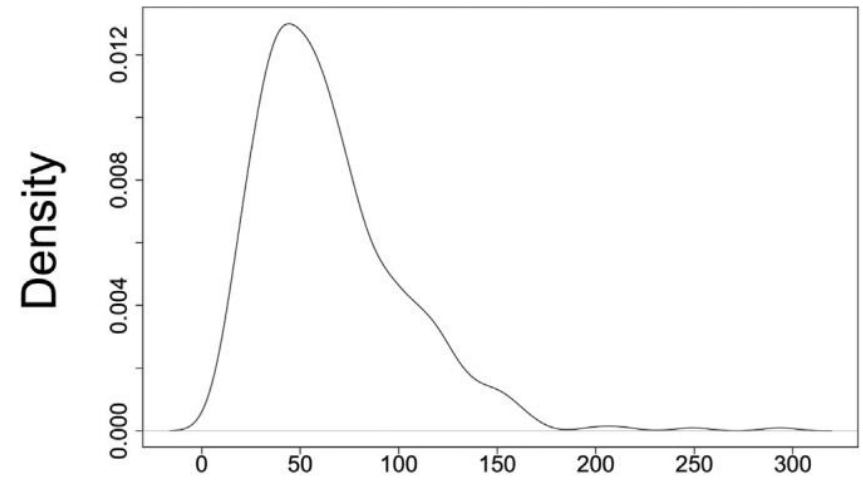

Fixation distance (m)

Fig. 7. Fixation-distance density plot. 
other typologies of road advertisements such as vendor signs, gas price LED signs, movable display boards, and commercial directional signs (both single and multiple). Fixation rate was highest for billboards (0.31) and was progressively lower for gas price LED signs (0.27), single directional signs ( 0.23$)$, vendor signs (0.23), multiple directional signs

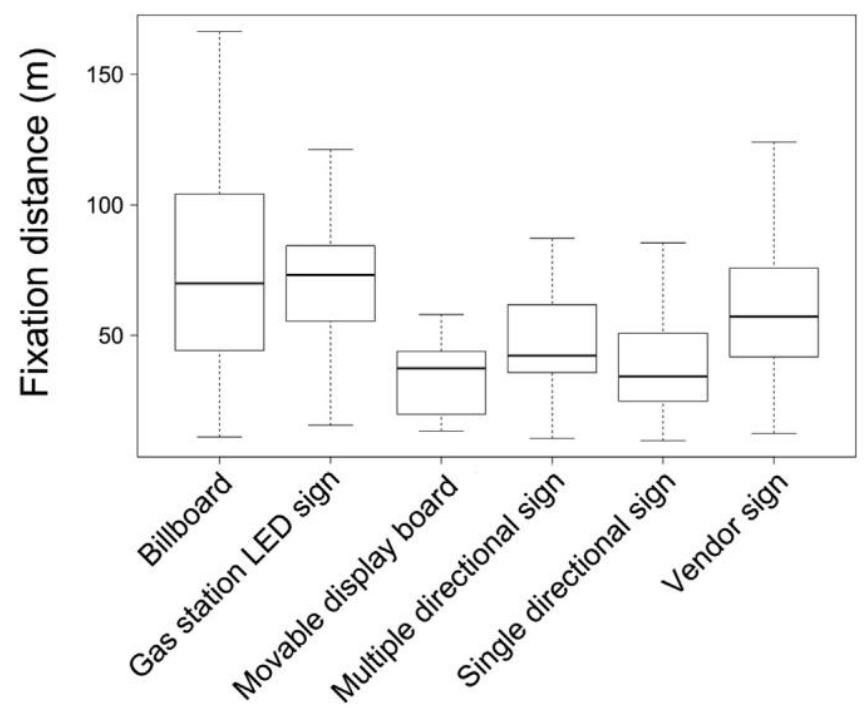

Fig. 8. Fixation-distance boxplots for the six roadside advertisement categories.

(0.16), and movable display boards (0.12). This effect could be explained by the higher conspicuity and saliency of billboards in comparison to vendor signs, probably due to their higher size, and the higher conspicuity and saliency of vendor signs in comparison to movable display boards and directional signs. In addition, billboards and vendor signs tended to have a higher textual content with large-size characters, and the amount of large-size text included in a roadside advertisement was one of the best predictors of both fixation rate and fixation duration.

Advertising signs that were placed on the driving side were fixated more (0.27) than the signs placed on the opposite side (0.21), and the lower was the lateral offset of the advertisement from the road the higher was the proportion of fixations. A higher lateral offset of the roadside advertisement implied that the driver had to make a large saccadic movement to foveate the sign, and that the sign was firstly processed in a more peripheral visual field, where vision accuracy is lower (Costa et al., 2018a,b; Crundall et al., 2002).

This result was also confirmed by the multiple linear regression in which clearance from the road was a significant predictor of fixation rate. Other significant predictors of advertising sign fixation were related to the amount of text included in the sign. The amount of text with characters greater than $10 \mathrm{~cm}$ induced a higher fixation rate, whereas the amount of small characters $(\leq 10 \mathrm{~cm})$ and in general long texts were related to a lower fixation rate. Advertising signs with long textual display probably fail to attract the driver's visual attention due to the poor readability in a dynamic context.

The distribution of fixation duration for advertising signs was strongly asymmetrical and positively skewed, with a median value of $297 \mathrm{~ms}$. This mean duration was higher in comparison to the mean fixation duration of $154 \mathrm{~ms}$ for traffic signs found in Costa et al. (2014). This might be explained by the higher visual complexity of advertising signs in comparison to traffic signs. The distribution had a long tail for long fixation intervals. For example, $24.8 \%$ of fixations on a single sign had a total duration of more than $500 \mathrm{~ms}, 16.1 \%$ exceeded $750 \mathrm{~ms}, 9.8 \%$ exceeded $1 \mathrm{~s}$, and $1.5 \%$ exceeded $2 \mathrm{~s}$. This is in line with the results of the review by Decker et al. (2015) who found that about 10-20\% of all glances towards billboards lasted more than $750 \mathrm{~ms}$. Considering that $750 \mathrm{~ms}$ has been suggested as the minimum perception-reaction time for a vehicle slowing ahead of the driver (Smiley et al., 2004), and that $2 \mathrm{~s}$ or longer eyes-off-the-road interval is strongly associated with motor vehicle collisions and other traffic incidents (Klauer et al., 2006), we can conclude that there is a discrete amount of cases in which distraction induced by roadside advertisement could adversely impact traffic safety.

Fixation duration was not affected by the advertising sign category and was inversely related to speed and elevation from the road and positively related to the number of medium size characters. Longer fixations to advertising signs positioned near the road level is in line with the results of Crundall et al. (2006), who compared in a simulator study visual patterns for street-level advertisements to raised-level advertisements, finding that street-level advertisements received longer fixations.

Fixation distance exhibited also a positively skewed distribution with a predominance of short distances and a long tail for long distances. Median value for fixation distance was $58.10 \mathrm{~m}$, a value that strongly mirrored the $51 \mathrm{~m}$ distance found for traffic signs (Costa et al., 2018a,b). This result should be weighted considering that the average speed was $55.54 \mathrm{~km} / \mathrm{h}$. Interestingly, fixation distance differed according to the advertising sign category, being highest for gas price LED displays $(73.16 \mathrm{~m})$, and progressively lower for billboards $(69.9 \mathrm{~m})$, vendor signs $(57.27 \mathrm{~m})$, multiple directional signs (42.10 m), movable display boards $(37.3 \mathrm{~m})$, and single directional signs $(34.25 \mathrm{~m})$, mirroring the size of the signs in the different categories. The distance at which advertising signs were fixated increased linearly with speed, sign size, and text length. These results could also help designers to optimize advertising sign layout and graphical content since distance and speed significantly affect the level of details and the amount of information that can be retained by a driver. 
It is important to state that an eye fixation to an advertising sign does not necessarily implies a driver's explicit awareness of the sign content. Foveal fixation is necessary for a detailed vision, but in many cases is not sufficient for awareness (Luoma, 1984; Schütz et al., 2011). This aspect is further supported considering that the median value for fixation duration was quite short $(297 \mathrm{~ms})$, and that fixations were recorded in a highly dynamic context. Furthermore, in this study the probability to attract eye fixations was assessed on a macro level, considering the whole sign area. Future studies with the use of eye recording devices with higher spatial and temporal resolution could investigate how the advertisement image features (i.e., luminance, contrast, color, text positioning and style) could affect the driver's scan path when exploring roadside advertisements. These studies could complement those that have modeled the influence of image features on fixation selection in naturalistic scenes (Nuthmann and Einhäuser, 2015; Nuthmann et al., 2017).

External distraction accounts for approximately 6-9\% of all motorvehicle collisions, and approximately $4 \%$ of all motor-vehicle collisions are caused by driver's errors (NHTSA, 2016). In a review of laboratory experiments, Wallace (2003) suggested that distraction accounts for roughly between $10 \%$ and $30 \%$ of all accidents. Therefore, the study of driver's visual behavior in response to sources of external distraction as advertising signs is of primary importance. In our study we showed that, although the proportion of advertising signs that are actually fixated was relatively low (0.24), and that the median of glance duration was rather short (297 $\mathrm{ms}$ ), there was a significant amount of "long" fixations that in the circumstance of an immediate reaction required by the driver, could pose serious problems for traffic safety. Analyses of the 100 Car Study of high-mileage drivers clearly indicated that longer eye glances off the road were associated with a greater risk of accidents (Dingus et al., 2006). Specifically, eye glances away from the forward roadway of $2 \mathrm{~s}$ duration doubled the risk of a crash or near crash (Klauer et al., 2006; Klauer et al., 2010). In our case, we had 1.1\% of advertising signs with a mean glance duration higher than $2 \mathrm{~s}$, and $10 \%$ of the advertising signs received a glance higher than $1 \mathrm{~s}$, a distraction interval that could adversely impact traffic safety, especially in urban contexts, where the visual scene tends to be more complex. For example, among the six advertising signs that attracted the higher fixation duration we recorded two vendor signs and a gas price led sign.

In this research, we have highlighted that advertising signs other than billboards could have a significant distracting potential. Vendor signs, in particular, tend to be more frequent than billboards, and in many cases their size, visual complexity, and textual content is higher, determining a serious distraction source for drivers. They are mainly distributed in urban areas and the glance duration to vendor signs (264 ms) was similar to that of billboards ( $330 \mathrm{~ms})$, and therefore they are a concrete source of distraction for drivers.

Advertising signs are the result of a difficult balancing between the opposite requirements of traffic safety and advertising effectiveness. As far as road safety is concerned, advertising signs are a form of external distraction with potential detrimental effects on driving-relevant tasks. To the contrary, advertisement efficacy is proportional to the amount of attention that is captured from the driver. When assessing the distracting potential of an advertising sign (i.e., fixation rate and fixation duration) the critical factors that emerged from this study were the clearance from the road and the amount of text included in the advertising sign. Distraction increases when the advertising sign is placed near the road. The text included in the advertisement induce the driver to read, an activity that requires much more time than capturing the graphical content. Examining the advertising signs that received the highest proportions of fixation rate and fixation duration, as shown in Figs. 5 and 6, it is clear that the majority were characterized by a conspicuous textual content. National highway regulations should incorporate the results of this study establishing limits for size, placement and character content that could help limiting the potential distracting effect of the various roadside advertising signs. Regulations should focus not only on billboards but also on vendor signs, commercial directional signs, gas price LED displays, and movable display boards since all compete with the driver's attention undermining traffic safety. Acknowledgement

The research was supported by the Alma Idea 2017 Costa grant from the University of Bologna.

\section{References}

Ady, R., 1967. An investigation of the relationship between illuminated advertising signs and expressway accidents. Traffic Saf. Res. Rev. 3, 9-11.

Beijer, D., Smiley, A., Eizenman, M., 2004. Observed driver glance behavior at roadside advertising signs. Transport. Res. Rec.: J. Transportat. Res. Board 1899, 96-103. https://doi.org/10.3141/1899-13.

Belyusar, D., Reimer, B., Mehler, B., Coughlin, J.F., 2016. A field study on the effects of digital billboards on glance behavior during highway driving. Accid. Anal. Prev. 88, 88-96. https://doi.org/10.1016/j.aap.2015.12.014.

Bendak, S., Al-Saleh, K., 2010. The role of roadside advertising signs in distracting drivers. Int. J. Ind. Ergon. 40 (3), 233-236. https://doi.org/10.1016/j.ergon.2009.12. 001.

Chan, M., Singhal, A., 2013. The emotional side of cognitive distraction: implications for road safety. Accid. Anal. Prev. 50, 147-154. https://doi.org/10.1016/j.aap.2012.04. 004.

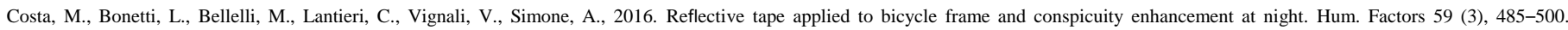
https://doi.org/10.1177/0018720816677145.

Costa, M., Bonetti, L., Vignali, V., Lantieri, C., Simone, A., 2018a. The role of peripheral vision in vertical road sign identification and discrimination. Ergonomics. https:// doi.org/https://doi.org/10.1080/00140139.2018.1508756.

Costa, M., Simone, A., Vignali, V., Lantieri, C., Bucchi, A., Dondi, G., 2014. Looking behavior for vertical road signs. Transport. Res. F Traffic Psychol. Behav. 23, 147-155.

Costa, M., Simone, A., Vignali, V., Lantieri, C., Palena, N., 2018b. Fixation distance and fixation duration to vertical road signs. Appl. Ergon. 69, 48-57. https://doi.org/10. 1016/J.APERGO.2017.12.017.

Crundall, D., Underwood, G., 1998. The effects of experience and processing demands on visual information acquisition in drivers. Ergonomics 41, 448-458.

Crundall, D., Underwood, G., Chapman, P., 2002. Attending to the peripheral world while driving. Appl. Cognit. Psychol. 16, 459-475.

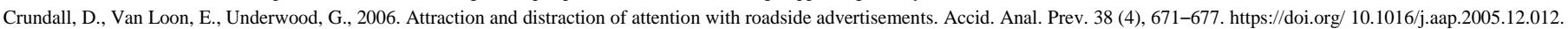

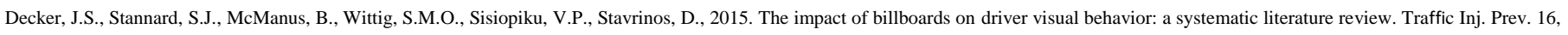
234-239. https://doi.org/10.1080/15389588.2014. 936407.

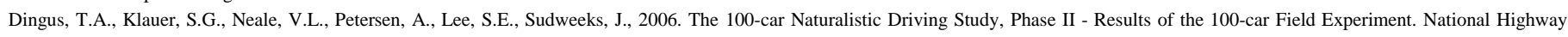
Traffic Safety Administration, Washington, DC.

Edquist, J., Horberry, T., Hosking, S., Johnston, I., 2011. Effects of advertising billboards during simulated driving. Appl. Ergon. 42 (4), 619-626. https://doi.org/10.1016/j. apergo.2010.08.013.

Elliot, A.J., Maier, M.A., 2014. Color psychology: effects of perceiving color on psychological functioning in humans. Annu. Rev. Psychol. 65, 95-120. https://doi.org/10. 1146/annurev-psych010213-115035.

Holmqvist, K., Nystrom, M., Andersson, R., Dewhurst, R., Jarodzka, H., van de Weijer, J., 2015. Eye Tracking. Oxford University Press, Oxford.

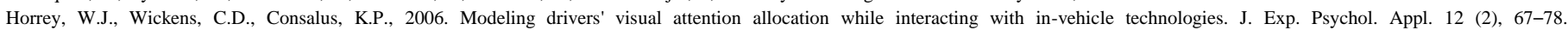
https://doi.org/10.1037/1076-898X.12.2.67.

Italian Highway Code, 1992. D.L. 285, April 30th 1992.

Kaber, D., Pankok, C., Corbett, B., Ma, W., Hummer, J., Rasdorf, W., 2015. Driver behavior in use of guide and logo signs under distraction and complex roadway conditions. Appl. Ergon. 47, 99106. https://doi.org/10.1016/j.apergo.2014.09.005.

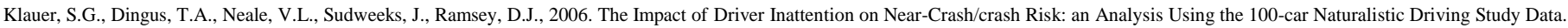
NHTSA, Washington, DC. 
Klauer, S.G., Guo, F., Sudweeks, J.D., Dingus, T.A., 2010. An Analysis of Driver Inattention Using a Case-Crossover Approach on 100-car Data: Final Report. U.S. Department of Transportation: National Highway Traffic Safety Administration.

Land, M.F., Lee, D.N., 1994. Where we look when we steer. Nature 369 (6483), 742-744. https://doi.org/10.1038/369742a0

Land, M.F., Tatler, B.W., 2009. Looking and Acting: Vision and Eye Movements in Natural Behaviour. Oxford University Press, Oxford.

Lansdown, T.C., Stephens, A.N., Walker, G.H., 2015. Multiple driver distractions: a systemic transport problem. Accid. Anal. Prev. 74, 360-367. https://doi.org/10.1016/j. aap.2014.07.006.

Lantieri, C., Lamperti, R., Simone, A., Costa, M., Vignali, V., Sangiorgi, C., Dondi, G., 2015. Gateway design assessment in the transition from high to low speed areas. Transport. Res. F Traffic Psychol. Behav. 34, 41-53. https://doi.org/10.1016/j.trf. 2015.07.017.

Lesley, G., 1995. Enhancing the daytime conspicuity of pedestrians through the usage of fluorescent materials. Color Res. Appl. 20 (2), 117-123. https://doi.org/10.1002/col. 5080200207.

Luoma, J., 1984. Perception and eye movements in simulated traffic situations. Acta Ophthalmol. 161, 128-134.

Marciano, H., Yeshurun, Y., 2012. Perceptual load in central and peripheral regions and its effects on driving performance: advertising billboards. Work 41 (Suppl. 1), $3181-3188$. https://doi.org/10.3233/WOR-2012-0580-3181.

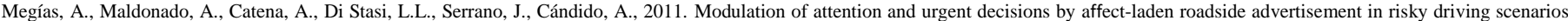
Saf. Sci. 49 (10), 1388-1393. https://doi.org/10.1016/j. ssci.2011.06.001.

Mourant, R.R., Rockwell, T.H., 1972. Strategies of visual search by novice and experienced drivers. Hum. Factors 14, 325-335.

NHTSA, 2016. Traffic Safety Facts: Research Note. NHTSA, Washington, DC.

Nuthmann, A., Einhäuser, W., 2015. A new approach to modeling the influence of image features on fixation selection in scenes. Ann. N. Y. Acad. Sci. https://doi.org/10. 1111/nyas.12705.

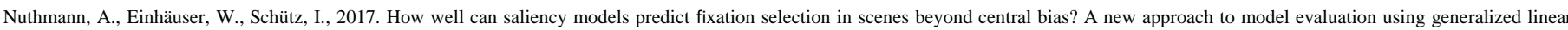
mixed models. Frontiers in Human Neuroscience. https:// doi.org/10.3389/fnhum.2017.00491.

Rayner, K., Rotello, C.M., Stewart, A.J., Keir, J., Duffy, S.A., 2001. Integrating text and pictorial information: eye movements when looking at print advertisements. J. Exp. Psychol. Appl. 7 (3), 219-226. https://doi.org/10.1037/1076-898X.7.3.219.

Schütz, A.C., Braun, D.I., Gegenfurtner, K.R., 2011. Eye movements and perception: a selective review. J. Vis. 11 (5), 1-30. https://doi.org/10.1167/11.5.9.

Smiley, A., Smahel, T., Eizenman, M., 2004. Impact of video advertising on driver fixation patterns. Transport. Res. Rec. 1899 (1), 76-83. https://doi.org/10.3141/1899-10.

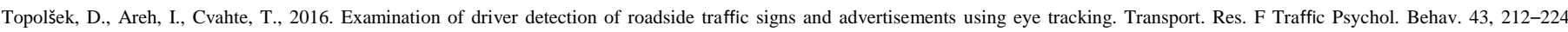
https://doi.org/10.1016/j.trf.2016.10.002

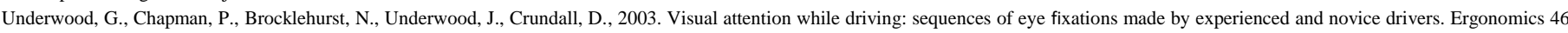
(6), 629-646. https://doi.org/10.1080/0014013031000090116.

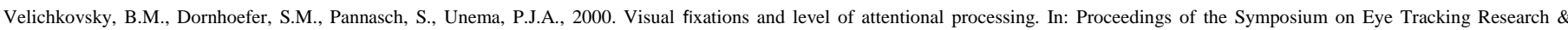
Applications - ETRA '00, pp. 79-85. https://doi.org/10.1145/355017.355029.

Wallace, B., 2003. Driver distraction by advertising: genuine risk or urban mith? Municip. Eng. 156 (3), 185-190.

Wickens, C.D., 2007. Attention to attention and its applications: a concluding view. In: Kramer, A.F., Wiegmann, D.A., Kirlik, A. (Eds.), Attention: from Theory to Practice. Oxford University Press, Oxford.

Wickens, C.D., 2008. Multiple resources and mental workload. Hum. Factors: J. Hum. Factors Ergonom. Soc. 50 (3), 449-455. https://doi.org/10.1518/ 001872008X288394.

Wickens, C.D., McCarley, J.S., 2008. Applied Attention Theory. CRC Press, Boca Raton.

Young, M.S., Mahfoud, J.M., Stanton, N.A., Salmon, P.M., Jenkins, D.P., Walker, G.H., 2009. Conflicts of interest: the implications of roadside advertising for driver attention. Transport. Res. F Traffic Psychol. Behav. 12 (5), 381-388. https://doi.org/10.

$1016 /$ j.trf.2009.05.004. 